\begin{tabular}{|l|l|l||}
\hline \multicolumn{2}{|c|}{ PublisherInfo } \\
\hline \hline PublisherName & $:$ & BioMed Central \\
\hline \hline PublisherLocation & $:$ & London \\
\hline \hline PublisherImprintName & $:$ & BioMed Central \\
\hline \hline
\end{tabular}

\title{
What centrosomes can teach us about tumor progression
}

\begin{tabular}{|l|l|l||}
\hline \multicolumn{2}{|c|}{ ArticleInfo } \\
\hline \hline ArticleID & $:$ & 3797 \\
\hline \hline ArticleDOI & $:$ & $10.1186 /$ bcr-2002-76551 \\
\hline \hline ArticleCitationID & $:$ & 76551 \\
\hline \hline ArticleSequenceNumber & $:$ & 20 \\
\hline \hline ArticleCategory & $:$ & Paper Report \\
\hline \hline ArticleFirstPage & $:$ & 1 \\
\hline \hline ArticleLastPage & $:$ & 3 \\
\hline \hline & & RegistrationDate $: 2002-3-19$ \\
& $:$ & Received \\
\hline ArticleHistory & Accepted 2002-3-19 \\
& $:$ 2002-4-8 \\
\hline \hline ArticleCopyright & $:$ & Biomed Central Ltd2002 \\
\hline \hline ArticleGrants & $:$ & \\
\hline \hline ArticleContext & $:$ & 1305844 \\
\hline \hline
\end{tabular}


Karen Schmeichel, ${ }^{\text {Affl }}$

Aff1 Lawrence Berkeley National Laboratory, Berkeley, CA, USA

\section{Keywords}

Aneuploidy, breast tumor progression, centrosomes, chrosomal instability, microtubules, p53

\section{Context}

During mitosis, centrosomes organize microtubules into spindle structures that mediate proper chromosomal segregation. Increased centrosome number, a characteristic common to a majority of breast tumors, is thought to cause chromosomal mis-segregations and thus lead to tumor aneuploidy. Because interphase centrosomes nucleate and organize the microtubule cytoskeleton, centrosome abnormalities could also contribute to cellular malignancy by disrupting overall cellular architecture. Given the dual significance of the centrosome, the authors examined the relationship between centrosomes (i.e. number, size and activity) and chromosomal instability (CIN), p53 mutation, tissue differentiation and aneuploidy in a total of 27 tissue samples from either normal breast $(\mathrm{n}=7)$ or from tumors of five histologic grades ( diploid [ $n=3]$, monosomy $17[\mathrm{n}=3]$, stable aneuploid [n $=5]$, unstable aneuploid $[\mathrm{n}=9])$.

\section{Significant findings}

In primary breast tissue samples, amplification of both centrosome size and number correlated directly with CIN and aneuploidy. This correlation was independent of p53 status, thus centrosome amplifications driving CIN may be due to molecular lesions other than p53 mutation. Alterations in centrosome function, as measured by increased microtubule nucleation capacity, did not correlate with centrosome amplification, CIN and aneuploidy. However, nucleation activity increased with loss of tissue differentiation; undifferentiated aneuploid tumors, especially those with p53 mutations, showed a higher level of nucleating activity than lower grade tumors. Finally, centrosome amplification was detected in in situ ductal carcinomas, suggesting that centrosome defects drive chromosomal irregularities at an early stage in tumor progression. 


\section{Comments}

The study essentially dissects two independent consequences of aberrant centrosome behavior: 1) size and number correlate with chromosomal abnormalities and 2) microtubule nucleating function is associated with loss of tumor differentiation. They suggest that these distinct effects can be attributed to the two known functions of the centrosome with number and function being most closely related to spindle assembly during mitosis, and with the inflated nucleating activity being linked to cytoskeletal integrity and tissue architecture. Although the idea that centromsome defects intensify tumorgenic potential through cytoskeletal rearrangements is highly provocative, conclusive evidence in its support is not presented. Additional studies that increase the sample pool, especially with the lower grade tumors, are needed to demonstrate general applicability of the study's findings. This study justifies more serious consideration of centrosomes as targets for the diagnosis and therapy of breast cancer. Identifying regulators of centrosome size and duplication may lead to strategies to protect against early events of breast cancer progression. In later grade tumors, inhibitors of centrosome nucleation activity may be useful for suppressing those events that affect the differentiation status of the tumor.

\section{Methods}

Confocal microscopy, immunofluorescence, electron microscopy, in vitro microtubule nucleation assays, FISH analysis, denaturing HPLC screen for p53 mutations, Kendall's t-test

\section{References}

1. Lingle W, Barrett SL, Negron VC, D'Assoro AB, Boeneman K, Liu W, Whitehead CM, Reynolds C, Salisbury JL: Centrosome amplification drives chromosomal instability in breast tumor development.

This PDF file was created after publication. 